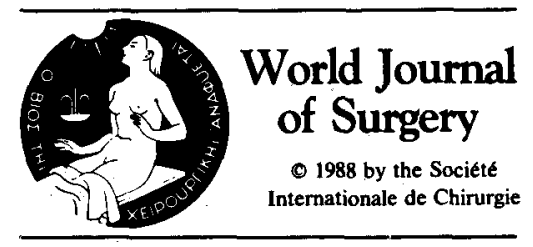

\title{
Deaths Due to Differentiated Thyroid Cancer: A 46-Year Perspective
}

\author{
Jay K. Harness, M.D., F.A.C.S., Michael K. McLeod, M.D., F.A.C.S., \\ Norman W. Thompson, M.D., F.A.C.S., Walter C. Noble, M.D., and Richard E. Burney, M.D., F.A.C.S. \\ Department of Surgery, Section of General Surgery, University of Michigan Medical Center, Ann Arbor, Michigan, U.S.A.
}

From 1940 to 1986 , a total of 798 patients were treated for differentiated thyroid carcinoma. One hundred and seventy-two patients died during the follow-up period: $42(24.4 \%)$ patients from thyroid cancer, $14(8.1 \%)$ from other causes with extensive thyroid cancer present, $75(43.6 \%)$ with no thyroid cancer, and $41(\mathbf{2 3 . 8 \%})$ with an unknown status of thyroid cancer.

Of the $\mathbf{4 2}$ patients dying due to thyroid cancer, 15 were male and 27 , female. Mean age at diagnosis was $48.3 \pm 17.7$ years with one-third of patients age 45 or younger at the time of the initial diagnosis. The primary tumors were large $(>4 \mathrm{~cm})$ and $59.5 \%$ of the patients had local invasion and/or cervical metastasis. Distant metastases were present in $9(21.4 \%)$ patients at the time of diagnosis.

Surgical therapy included total thyroidectomy $(72.1 \%)$ and limited or radical neck dissection $(69.4 \%)$. Radioactive iodine $\left({ }^{131} \mathrm{I}\right)$ was used to treat residual cancer and/or distant metastasis in $73.8 \%$ of the patients. External radiation therapy was used to treat locally advanced or recurrent disease in $52.3 \%$ of the patients.

Distant metastases and local recurrence were identified earlier in patients with follicular thyroid cancer whose survival time and diseasefree interval were significantly shorter $(p<0.001)$ than that of patients with papillary neoplasms. However, the survival and disease-free intervals were often very long in both papillary and follicular thyroid cancer deaths.

Onset of differentiated thyroid cancer before the age of 40 years does not preclude serious sequelae and death. Since no known histopathologic features can consistently predict outcome, we continue to advocate aggressive treatment of all patients with differentiated thyroid cancer.

Several factors have been associated with a poor prognosis in differentiated thyroid cancer including age (males $>40 \mathrm{yr}$, females $>50 \mathrm{yr}$ ), male sex, and tumor characteristics such as size $(>1.5 \mathrm{~cm})$, capsular and vascular invasion, extent, type, and grade [1-6]. No single microscopic or ultrastructural feature has emerged as a reliable means of predicting a fatal outcome. Of these factors, age at initial diagnosis is considered to be the single most important indicator of eventual outcome [3]. The extent of thyroidectomy as a determinant of outcome, especially in patients under age 45 years, continues to be

Presented at the International Association of Endocrine Surgeons in Sydney, Australia, September, 1987.

Reprint requests: Jay K. Harness, M.D., F.A.C.S., Department of Surgery, University of Michigan Medical Center, $2920 \mathrm{~F}$ Taubman Health Care Center, Box 0331, 1500 E. Medical Center Drive, Ann Arbor, Michigan 48109-0331, U.S.A. debated among experienced thyroid surgeons, and remains an unsolved controversy.

In 1964, Tollefsen reported 70 fatal cases of papillary cancer [1]. Other reports have added to Tollefsen's findings and have emphasized the often long periods of time observed from the time of initial diagnosis and treatment to the time of eventual recurrence and death $[5,6]$. Series reporting only 10- to 15-year follow-ups are less meaningful since documented instances of recurrence occur 15-25 years following initial treatment and death may occur as long as $\mathbf{3 0}$ years following initial therapy.

We review the 46-year experience at the University of Michigan, Ann Arbor, Michigan, U.S.A. in an effort to further define prognostic factors found in fatal differentiated thyroid cancer.

\section{Methods}

The Cancer Registry (Department of Medical Information, University of Michigan Hospitals) maintains a record of all patients with malignant neoplasms seen at this institution. The registry was searched for all patients with the diagnosis of differentiated papillary and/or follicular thyroid cancer seen between 1940 and 1986. Patients with medullary, anaplastic, Hürthle cell, and lymphomatous neoplasms of the thyroid were excluded. The registry was then searched to determine which patients were known to have died and the status of their thyroid neoplasm at death. The medical records of all deceased patients with thyroid cancer were reviewed by one or more of the authors. All data were recorded on a predetermined survey form that included demographic data, sex, age at diagnosis, type and duration of symptoms, tumor size, number and type of operations performed, uptake of radioiodine, treatment with radioiodine, external radiation therapy or chemotherapy, presence of local or distant metastases at the time of diagnosis, interval between initial treatment and discovery of local or distant recurrence, length of follow-up, and cause of death.

Copies of pertinent summaries, operative notes, pathology reports (including autopsy reports), clinic visits, and death certificates were reviewed. Only the pathologic reports of the University of Michigan Hospitals were accepted for determining cell type. When the cause of death could not be determined from the medical record, telephone inquiry was made to obtain 
Table 1. Distribution of thyroid neoplasms by sex and cell type.

\begin{tabular}{llll} 
& Follicular & Papillary & Total \\
\hline Men & $23(13.9 \%)$ & $143(86.1 \%)$ & 166 \\
Women & $140(22.2 \%)$ & $492(77.8 \%)$ & 632 \\
Total & 163 & 635 & $798(100 \%)$ \\
\hline
\end{tabular}

information about the cause of death and status of the patient's thyroid carcinoma at the time of death. Data were compiled and analyzed using a statistical analysis program designed for large data bases (MIDAS, University of Michigan Computer Center).

\section{Results}

From 1940 to 1986 , a total of 832 cases of differentiated thyroid cancer were recorded by the Cancer Registry at the University of Michigan Hospitals. Thirty-four patients were found to have cancer at autopsy or as an incidental finding during major head and neck surgery and were excluded from this report since they had not undergone treatment for primary thyroid cancer. Of the remaining 798 patients, the sex and thyroid cancer histology is shown in Table 1 . Of these 798 patients, 626 were alive at the end of 1986. Of the 172 who had died: 42 (24.4\%) patients died from thyroid cancer, $14(8.1 \%)$ died from concurrent disease with thyroid cancer present, 75 (43.6\%) died with no thyroid cancer present; and $41(23.8 \%)$ died with the status of their thyroid cancer unknown (Fig. 1). In the group in whom the thyroid cancer status was unknown, there were no cases of documented recurrence, distant metastasis, or active thyroid cancer at the time of the patients' last follow-up visits.

Death was caused by thyroid cancer in $5.3 \%$ of the patients. Thyroid cancer was present, but not the cause of death in $1.8 \%$ (Fig. 2). All 14 of these patients had extensive local or metastatic thyroid cancer present at the time of death from other causes. No cancer was present in $9.4 \%$ of the patients; and $5.1 \%$ of the patients died without records of their thyroid cancer status.

\section{Histology}

Twenty-eight (66.7\%) neoplasms were classified as papillary, or follicular variant of papillary. Fourteen (33.3\%) cancers were classified as follicular carcinoma, and contained no papillary changes. Although Hürthle cell changes were present in some tumors, there were no Hürthle cell tumors in this group. None of the 42 carcinomas showed anaplastic degeneration at the time of original diagnosis.

\section{Age and Sex}

The mean age at diagnosis of the 42 patients who died from thyroid cancer was $48.3 \pm 17.7$ years (range, 6-77 yr). Patients dying from follicular cancer were equally divided among the sexes and were older at the time of diagnosis than their counterparts with papillary carcinoma [mean age, 57.1 \pm 12.3 years (range, 40-77 yr) versus 43.8 \pm 18.5 years (range, 6-69 yr)]. The age of onset was similar for males and females with follicular carcinoma: males, 56.6 years (range, 40-76 yr); females, 57.7 years (range, 41-77 yr). In contrast, of the 28

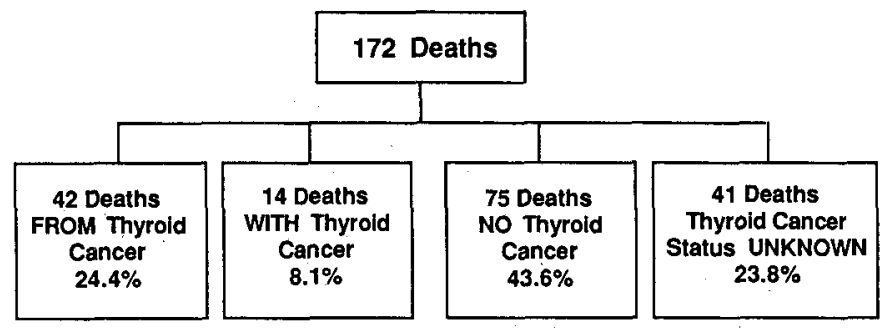

Fig. 1. Breakdown of deaths by category and percentage.

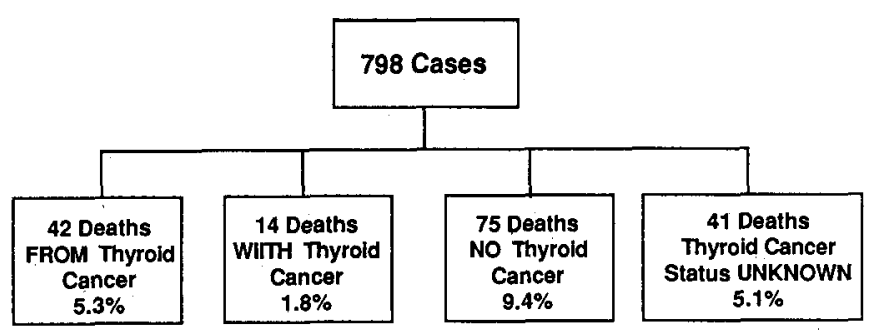

Fig. 2. Breakdown of deaths by category and percentage as compared to entire group of cases.

patients who died of papillary cancer, 8 were male and 20 were female. The average age at diagnosis of the 8 males with papillary cancer was 50.9 years (range, 11-68 yr) and of the 20 females was 41 years (range, 6-69 yr).

\section{Extent of Initial Cancer}

For 15 of 42 cases, size of tumor was noted in the pathologic or operative records (Table 2). These tumors were notable for both their large size and extrathyroidal extension. Local invasion, palpable metastatic cervical lymph nodes, or both, were found in $25(59.5 \%)$ patients. Initial metastases to lung (6 patients), bone ( 2 patients), or other sites ( 1 patient) was seen in 9 (21.4\%) patients. When categorized histologically, $16.0 \%$ of papillary and $41.7 \%$ of follicular cancers had initial distant metastasis.

\section{Surgical Therapy}

Table 2 lists the surgical procedures performed on the 42 patients. A much higher percentage $(78.5 \%)$ of the papillary cases had an initial or completion total thyroidectomy than the follicular cases (57.2\%). Conversely, a higher percentage of the follicular cancer patients (42.9\%) had no lymph node procedures performed than did the papillary patients $(22.7 \%)$. Sixteen patients $(38 \%)$ had a previous thyroid operation prior to their referral to our medical center. Thirty-three (78.6\%) of the 42 patients were referred to our medical center for therapy after a diagnosis of thyroid cancer had been established. The category, "other," includes such procedures as lymph node biopsy and tumor debulking.

For the past 35 years, total thyroidectomy following intraoperative frozen section to confirm presence of malignancy has been performed for treatment of differentiated thyroid neoplasms. In patients referred after less than "total" thyroidectomy, completion thyroidectomy is done to facilitate the use of radioactive iodine and to remove any residual thyroid neo- 
Table 2. Mean tumor size and surgical therapy.

\begin{tabular}{|c|c|c|c|}
\hline \multirow[b]{2}{*}{ Type of operation } & \multicolumn{3}{|c|}{ Mean tumor size $(\mathrm{cm})$} \\
\hline & All cases $(\%)$ & Papillary $(\%)$ & Follicular (\%) \\
\hline Total thyroidectomy & 51.2 & 57.1 & 42.9 \\
\hline Completion thyroidectomy & 20.9 & 21.4 & 14.3 \\
\hline Total & 72.1 & 78.5 & 57.2 \\
\hline Subtotal thyroidectomy & 20.9 & 14.3 & 35.7 \\
\hline Other & 7.0 & 7.1 & 7.1 \\
\hline Lymph node sampling & 30.6 & 27.3 & 35.7 \\
\hline Modified radical neck dissection & 22.2 & 27.3 & 14.3 \\
\hline Radical neck dissection & 13.9 & 18.2 & 7.1 \\
\hline Regional lymph node dissection & 2.8 & 4.5 & 0.0 \\
\hline No lymph node dissection & 30.6 & 22.7 & 42.9 \\
\hline
\end{tabular}

Table 3. ${ }^{131}$ I therapy.

\begin{tabular}{|c|c|c|c|}
\hline & All cases & Papillary & Follicular \\
\hline No. of patients treated & $31(73.8 \%)$ & $18(64.3 \%)$ & $13(92.9 \%)$ \\
\hline Total dose, (range) & $\begin{array}{l}326.1 \mathrm{mCi} \pm 206 \\
(91.9-966.0)\end{array}$ & $\begin{array}{c}302.5 \mathrm{mCi} \pm 205 \\
(91.9-966.0)\end{array}$ & $\begin{array}{c}370.3 \mathrm{mCi} \pm 212, \\
(91.9-805.9)\end{array}$ \\
\hline No. of treatments, (range) & $\begin{array}{l}2.5 \pm 2.5 \\
(1-11)\end{array}$ & $\begin{array}{l}2.9 \pm 3.2 \\
(1-11)\end{array}$ & $\begin{array}{l}2.1 \pm 1.0 \\
(1-4)\end{array}$ \\
\hline
\end{tabular}

plasm, if possible. The main objective in the operating room was primary surgical control of the thyroid cancer.

\section{Radioactive Iodine External Radiation Therapy and Chemotherapy}

Radioactive ${ }^{131} \mathrm{I}$ has been used for the treatment of regional and distant spread of differentiated thyroid cancer in our medical center since 1947 . All but 1 patient with follicular cancer and 18 of 28 papillary cancer patients received ${ }^{131}$ I therapy (Table 3 ). Those not treated had either no uptake of ${ }^{131} \mathrm{I}$ by their metastasis or the therapy was not available.

Radiation therapy was used in $22(52.3 \%)$ patients to control locally advanced or recurrent disease. Only 3 patients received chemotherapy during the final stages of their disease.

\section{Recurrent Disease}

Table 4 lists the data on the development of distant metastasis and regional recurrence. The data include those patients who presented with distant metastasis and those whose local/regional disease could not be cured.

What is highly significant $(p<0.001)$ is the difference in time of onset of both distant metastasis and regional recurrence of follicular cancer as compared to papillary. Follicular cancer was more rapidly progressive and difficult to manage. Distant metastases developed nearly 3 times faster $(33.5 \pm 43$ months versus $87.5 \pm 80.8$ months) in those with papillary tumors and regional recurrences, 6 times faster $(11.4 \pm 9.6$ months versus $68.7 \pm 60.8$ months). Papillary cancer typically metastasized to the lung $(48.0 \%)$ while follicular cancer was usually found in multiple sites $(46.2 \%)$.

The long time between initial diagnosis of papillary cancer and development of metastases was notable: up to 25 years $(300$ months) for distant metastases, and up to 17 years (204 months)
Table 4. Development of distant metastasis.

\begin{tabular}{llll}
\hline & All cases & Papillary & Follicular \\
\hline Incidence (\%) & 86.8 & 88.0 & 84.6 \\
Site of distant metastasis (\%) & & & \\
Lung & 42.1 & 48.0 & 30.8 \\
Bone & 2.6 & 0.0 & 7.7 \\
Multiple & 34.2 & 28.0 & 46.2 \\
Other & 7.9 & 12.0 & 0.0 \\
Time of onset (mo), (range) & $68.3 \pm 73.7$ & $87.5 \pm 80.8$ & $33.5 \pm 43$ \\
& $(0-300)$ & $(0-300)$ & $(0-132)$ \\
Regional recurrence & & 70.8 & 58.3 \\
Incidence (\%) & 66.7 & $68.7 \pm 60.8$ & $11.4 \pm 9.6$ \\
Time of onset (mo), (range) & $50.5 \pm 56.9$ & $(0-204)$ & $(2-24)$ \\
& $(0-204)$ & & \\
\hline
\end{tabular}

for regional recurrence. Illustrative cases deserve special review.

Case 1. A 62-year-old woman presented in 1953 with a 12month history of a progressively enlarging goiter. She underwent subtotal thyroidectomy for papillary carcinoma, and 11 years later developed a cervical metastasis which was treated by excision of the involved nodes, completion total thyroidectomy, and $194.0 \mathrm{mCi}$ of ${ }^{131} \mathrm{I}$. Fourteen years later ( 25 years after the initial diagnosis and treatment), she developed pulmonary metastases which did not take up ${ }^{131} \mathrm{I}$. She died of widespread pulmonary metastases 1 year later at age 88 (31 years after the initial diagnosis).

Case 2. A 30-year-old woman presented in 1947 with a 1-month history of a progressively enlarging neck mass. She was treated with a "near-total" thyroidectomy for her papillary thyroid cancer. Seventeen years later, the patient developed a recurrence in the neck which was treated by a radical neck dissec- 
Table 5. Survival and disease-free interval.

\begin{tabular}{|c|c|c|c|}
\hline & All cases & Papillary & Follicular \\
\hline Survival (yr), (range) & $\begin{array}{l}10.5 \pm 9.0 \\
(1 \mathrm{mo}-31 \mathrm{yr})\end{array}$ & $\begin{array}{l}13.0 \pm 9.7 \\
(3 \mathrm{mo}-31 \mathrm{yr})\end{array}$ & $\begin{array}{l}5.5 \pm 4.6 \\
(1 \mathrm{mo}-17 \mathrm{yr})\end{array}$ \\
\hline Disease-free (yr), (range) & $\begin{array}{c}5.3 \pm 6.7 \\
(0 \mathrm{mo}-24 \mathrm{yr})\end{array}$ & $\begin{array}{c}7.2 \pm 7.2 \\
(0 \mathrm{mo}-24 \mathrm{yr})\end{array}$ & $\begin{array}{l}1.5 \pm 2.9 \\
(0 \mathrm{mo}-11 \mathrm{yr})\end{array}$ \\
\hline
\end{tabular}

tion. Postoperative ${ }^{131} \mathrm{I}$ scanning demonstrated no uptake. Therefore, no ${ }^{131} \mathrm{I}$ therapy was given. Fourteen years later, at age 61 , the patient died of generalized carcinomatosis, 31 years after initial diagnosis and treatment.

\section{Survival and Disease-Free Interval}

Table 5 lists the mean survival and disease-free intervals for the 42 patients. The difference in mean survival between patients with papillary and follicular cancer is highly significant $(p<$ 0.001 ) and demonstrates the different biological behavior of these two cancers. Follicular cancer is more rapidly fatal, although the disease-free interval can demonstrate significant variation and very long periods may elapse (up to 24 years) prior to development of recurrent disease.

The next several cases illustrate the varied and prolonged course of many patients with ultimately fatal thyroid cancer, and show the sometimes fatal nature of thyroid cancer in patients under age 45 .

Case 3. A 21-year-old woman presented with a 4-month history of multinodular goiter in 1962. She underwent total thyroidectomy in an outside hospital for papillary cancer, and 1 month later had a right radical neck dissection for cervical metastasis. Within 4 months she developed left-sided cervical metastasis and was treated with a left radical neck dissection and external radiation therapy. We first saw her 25 months later for treatment of pulmonary metastases and administered $480 \mathrm{mCi}$ of ${ }^{131} \mathrm{I}$ in 4 doses over the following 8 years. Her pulmonary metastases stabilized, but never cleared, and she died of cancer at age 32 , nearly 11.5 years after the initial diagnosis.

Case 4. A 47-year-old male presented in 1964 with a 12-month history of a progressively enlarging right neck mass. He was treated for papillary thyroid cancer at an outside hospital with a right thyroid lobectomy. Eight years later he was referred to our medical center for a recurrent right neck mass. At operation, we found an extensive tumor with invasion of the brachial plexus. Completion total thyroidectomy and a modified radical neck dissection were performed. Postoperative ${ }^{131} \mathrm{I}$ scintiscanning demonstrated both cervical and pulmonary uptake. He was subsequently treated with $966.0 \mathrm{mCi}$ of ${ }^{131} \mathrm{I}$ in 5 doses over a 9 -year period. His pulmonary metastases stabilized, but never cleared. He died from his pulmonary metastases at age 65, 18 years after his initial diagnosis.

Case 5. A 6-year-old female received thymic irradiation during the first year of life in 1948. By age 6 she had developed a left thyroid mass with pulmonary metastases. She was treated at an outside hospital with a left thyroid lobectomy followed by 3,000 rads of external radiation therapy to the neck. She was subse- quently referred to the University of Michigan for completion total thyroidectomy and received $400 \mathrm{mCi}$ of ${ }^{131} \mathrm{I}$ in 11 doses over a 6-year period with complete clearing of her pulmonary metastases for the next 20 years. Her pulmonary metastases then recurred and she was treated with chemotherapy. She died at age 36, 30 years after her initial diagnosis and treatment.

\section{Discussion}

The report by Tollefsen et al. in 1964 focused attention on the general relationship between inadequate treatment of papillary cancer and subsequent death [1]. Nine (12.8\%) of their reported 70 deaths had pulmonary metastases when initially seen. The average age at diagnosis of the fatal cases was 52 years. Twenty $(29 \%)$ of the 70 patients had tumors larger than $5 \mathrm{~cm}$ in diameter. The cause of death was local recurrence in the neck in $40 \%$, pulmonary metastases in $31 \%$, bone metastases in $10 \%$, and metastases to other sites in $19 \%$ of patients. Thirty $(43 \%)$ of their patients were considered incurable when initially seen and uncontrolled locally recurrent cancer in the neck was the most common cause of death.

Subsequently, in 1973, Tollefsen et al. reported on their initial experience with follicular carcinoma of the thyroid [2]. Follicular cancer was found in older patients when compared to papillary cancer, and the incidence of initial distant metastasis was $9 \%$ and subsequent distant metastasis was $25 \%$. There was only a 70\% 5-year survival rate. Only in cases of distant metastases did they advocate total thyroidectomy in order that ${ }^{131}$ I could be used.

Cady et al. consider the age of the patient to be the key factor in survival from differentiated thyroid carcinoma and noted that $85 \%$ of deaths in their series occurred in patients older than 40 years of age [3]. "High-risk" patients were men over 40 and women over 50 years. All other patients were considered to be at "low-risk" for eventual death from thyroid carcinoma.

In 1981, Mazzaferri and Young reported on a 10-year follow-up of 576 papillary cancer patients [4]. The average age of their patients was 32.4 years (range, 6-75 yr). Mortality was nil in patients under age 30 years at initial diagnosis, or when the primary cancer was under $1.5 \mathrm{~cm}$ in diameter, even though 4 $(0.7 \%)$ had pulmonary metastasis at diagnosis. Local tumor invasion and cervical lymph node metastases had higher recurrence rates and markedly increased mortality. The time from initial treatment to recurrence averaged 55.6 \pm 9.4 months, and the highest recurrence rate was in patients receiving external radiation therapy and thyroid hormone replacement. Most importantly, the group of 310 patients who had an initial total thyroidectomy had significantly fewer recurrences $(p<0.01)$ than those treated initially by subtotal thyroidectomy.

In the last 2 years, 2 important series have been published [ 5 , 6]. Tubiana and co-workers reported 546 differentiated thyroid 
cancers [5]. He concluded that overall survival at 10 years is insufficient for assessing the efficacy of initial treatment because late relapses were frequent and long delays often occurred between relapse and death. In 12 of 49 relapsing patients, the recurrences occurred more than 20 years after the first treatment. Mortality increased sharply at age 45 and was higher in patients with moderately differentiated follicular cancers.

These data show that when follow-up is sufficiently long, relapses are more frequent than previously reported and death may occur 20-35 years after initial treatment. While the possibility of local recurrence or distant metastases decrease with time, it never disappears and they conclude that patients need lifelong follow-up.

McConahey et al. reported retrospectively on 859 patients with papillary thyroid cancer treated at the Mayo Clinic from 1946 to 1970 [6]. Their maximum follow-up was 39 years. Fifty-six $(6.5 \%)$ patients died from papillary cancer. Death was associated with age greater than 50 years, male sex, tumor size, tumor grade, initial extent of disease, and the absence of Hashimoto's disease. Mean time of death following operative treatment was 8.2 years (range, 1 mo-31 yr). With the appearance of a new distant metastatic lesion, $36 \%$ of patients died within 5 years and $65 \%$ within 20 years. There was a highly significant correlation $(p<0.001)$ between tumors $4 \mathrm{~cm}$ or larger in diameter and the development of either local recurrence or distant metastases. The risk of death increased with increased tumor size.

Our data are consistent with reports of similar large numbers of patients followed over long periods of time. Our patients who died had large, locally extensive tumors, frequently with initial distant metastases. Fifteen of our 42 deaths were in males (35.7\%), while males made up $20.8 \%$ of the original 798 cases.

While age remains an important prognostic factor in differentiated thyroid cancer, our data clearly demonstrates that death can occur in those aged 45 years and younger. Females in our series who died from papillary cancer had an average age of 41 years at initial diagnosis. Fully one-third of our 42 deaths from thyroid cancer were in patients who were 45 years old or younger, when their diagnosis was made. Younger patients are not immune to serious sequelae and death from thyroid cancer and they should be treated as aggressively as patients older than 45 years of age.

What is striking in our series of deaths, and similar to the report by Tubiana et al. [5], are the variably long times seen in the development of local recurrences and distant metastases (up to 25 years after initial treatment). Therefore, all patients with differentiated thyroid cancers require lifelong follow-up. Reports on the results of treatment for thyroid cancer need follow-ups of at least 20 years if the series are to be meaningful.

In our series, follicular cancer was very aggressive. These patients had significantly shorter survivals and disease-free intervals $(p<0.001)$. This experience is similar to others $[2,3$, $5]$ and demonstrates that papillary and follicular cancers are not considered as equivalent tumors with respect to prognosis.

The overall mortality from differentiated thyroid cancer in our review is $5.3 \%(42 / 798)$. If we assume that all of the 14 patients who died of their concurrent disease would have died from their thyroid cancers, then the cumulative mortality rate would be $7.1 \%(56 / 798)$. These results are similar to other reported series [2-6], and correct for the fact that the majority of thyroid cancer cases referred to our medical center have relatively advanced disease.

A consistent policy of total thyroidectomy for the treatment of all thyroid cancers greater than $1 \mathrm{~cm}$ has been followed at our institution since 1959. In our experience, total thyroidectomy plus appropriate cervical lymph node dissection is important not only to adequately control the cancer in the neck, but to allow the use of ${ }^{131} \mathrm{I}$ for the treatment of distant metastases. We continue to advocate such an aggressive approach until a biologic marker is found that will allow the identification of those patients whose disease is more aggressive and ultimately fatal.

\section{Résumé}

Entre 1940 et 1986, 798 patients au total ont été traités pour un cancer différencié de la thyroïde. Cent-soixant-douze patients sont morts par la suite: $42(24.4 \%)$ de leur cancer, $14(8.1 \%)$ d'une autre cause alors que des signes d'extension du cancer étaient présents, $75(43.6 \%)$ d'une autre cause sans signe de cancer, et $41(23.8 \%)$ sans qu'on ait pu connaître le stade du cancer.

Des 42 patients morts de leur cancer, il y avait 15 hommes et 27 femmes. L'âge moyen au moment du diagnostic était de 48.3 \pm 17.7 ans: un tiers des patients avait 45 ans ou moins au moment du diagnostic. Les tumeurs primitives avaient plus de $4 \mathrm{~cm}$ et $59.5 \%$ des patients présentaient un envahissement local et/ou une métastase cervicale. Les métastases à distance ont été détectées chez $9(21.4 \%)$ patients au moment du diagnostic.

Une thyroïdectomie totale a été effectuée chez $72.1 \%$ des patients, associée à un curage cervical limité ou radical chez 69.4\% des patients. Chez $73.8 \%$ des patients on a traité le tissu cancéreux résiduel et/ou des métastases à distance par de l'I 131. La radiothérapie a été utilisée pour traiter les patients présentant une extension importante ou une récidive chez $52.3 \%$ des patients.

Des métastases à distance et des récidives ont été identifiées précocement chez les patients ayant un cancer folliculaire. Dans ce groupe de patients, la survie et l'intervalle de temps sans maladie étaient significativement plus courts $(p<0.001)$ que chez les patients ayant un cancer papillaire. Il faut cependant noter que la survie et l'intervalle de temps sans maladie étaient très longs dans les 2 groupes de patients.

La découverte d'un cancer différencié de la thyroïde avant l'âge de 40 ans n'est pas un facteur pronostique particulier. Puisqu'il n'y pas de facteur histologique permettant de prévoir l'évolution, nous continuons de préconiser un traitement agressif chez tout patient présentant un cancer différencié de la thyroïde.

\section{Resumen}

En el período $1940-1986$, un total de 798 pacientes recibieron tratamiento para carcinoma tiroideo; 172 murieron en el curso del seguimiento: $42(24.4 \%)$ por cáncer tiroideo, $14(8.1 \%)$ por otras causas pero con presencia de extenso cáncer tiroideo, 75 (43.6\%) libres de cáncer tiroideo, y 41 (23.8\%) con estado desconocido en cuanto al cáncer tiroideo.

De 42 pacientes que murieron por cáncer tiroideo, 15 eran hombres y 27 , mujeres. Su edad promedio en el momento del 
diagnóstico fue $48.3 \pm 17.7$ años, con una tercera parte de los pacientes de 45 años o menos. Sus tumores primarios eran de tamaño grande $(>4 \mathrm{~cm})$ y $59.5 \%$ presentaban invasión local y/o metástasis cervicales. Se encontraron metástasis distantes en 9 (21.4\%) en el momento del diagnóstico.

La terapia quirúrgica incluyó tiroidectomía total $(72.1 \%)$ y disección radical o limitada del cuello (69.4\%); $73.8 \%$ de los pacientes recibieron yodo radioactivo $\left({ }^{131} \mathrm{I}\right)$ como tratamiento de cáncer residual y/o metástasis distantes. La radioterapia externa fue utilizada en el manejo de enfermedad local avanzada o enfermedad recurrente en $52.3 \%$ de los pacientes.

Metástasis distantes y recurrencia local fueron identificadas más tempranamente en pacientes con cáncer folicular cuya supervivencia y lapso de tiempo libre de enfermedad fueron significativamente más cortos $(p<0.001)$ que los de los pacientes con neoplasmas papilares. Sin embargo, las supervivencias y los lapsos libres de enfermedad con frecuencia aparecieron muy prolongados tanto en los muertos por cáncer papilar como en aquellos muertos por cáncer folicular.

La aparición del cáncer diferenciado de la glándula tiroides antes de los 40 años de edad no implica libertad de secuelas graves o de mortalidad. Puesto que se conocen características histopatológicas que puedan predecir en forma consistente el pronóstico, nosotros continuamos preconizando tratamiento agresivo en todo paciente con cáncer diferenciado de tiroides.

\section{References}

1. Tollefsen, H.R., DeCosse, J.J., Hutter, R.V.P.: Papillary carcinoma of the thyroid: A clinical and pathological study of 70 fatal cases. Cancer 17:1035, 1964

2. Tollefsen, H.R., Shah, J.P., Huvos, A.G.: Follicular carcinoma of the thyroid. Am. J. Surg. 126:523, 1973

3. Cady, B., Sedgwick, C.E., Meissner, W.A., Bookwalter, J.R., Romagosa, U., Werber, J.: Changing clinical, pathologic, therapeutic, and survival patterns in differentiated thyroid carcinoma. Ann. Surg. 184:541, 1976

4. Mazzaferri, E.L., Young, R.L.: Papillary thyroid carcinoma: A 10 year follow-up report of the impact of therapy in 576 patients. Am J. Med. 70:511, 1981

5. Tubiana, M., Schlumberger, M., Rougier, P., Laplanche, A., Benhamou, E., Gardet, P., Caillou, B., Travagli, J., Parmentier, C.: Long-term results and prognostic factors in patients with differentiated thyroid carcinoma. Cancer 55:794, 1985

6. McConahey, W.M., Hay, I.D., Woolner, L.B., van Heerden, J.A., Taylor, W.F.: Papillary thyroid cancer treated at the Mayo Clinic, 1946-1970: Initial manifestations, pathologic findings, therapy, and outcome. Mayo Clin. Proc. 61:978, 1986

\section{Invited Commentary}

\author{
Oliver H. Beahrs, M.D.
}

Department of Surgery, Mayo Clinic, Rochester, Minnesota, U.S.A.

This article adds further information regarding the biological behavior of the well-differentiated carcinomas of the thyroid gland. It also adds data that the pure papillary lesions including those with mixed papillary and follicular histologic components behave differently than the undifferentiated lesions. The latter are more rapidly progressive, spread to distant sites, and are more difficult to manage. Likewise, there is a higher death rate with the undifferentiated cancers. The papillary cancers typically spread to the lungs while the follicular cancer spreads to multiple distant sites and more frequently so than the papillary lesions. Follicular tumors have lymph node involvement less frequently than papillary lesions. Both types have a long life history.

Follicular cancers are generally seen in patients 1 decade older than patients with papillary lesions. The use of ${ }^{131} I$ is more frequently of value in the management of follicular lesions than papillary tumors.

From the factors mentioned above and recorded in this article, it should be clear that there is a difference in the histological pattern of papillary adenocarcinoma and pure follicular adenocarcinoma and that the biological behavior of the 2 lesions are somewhat different and data regarding each type should be reported separately. This is recognized and done in this article, but data is also reported regarding the combined series, which is of no value and leads to some confusion in reporting information about these 2 somewhat different well- differentiated cancers of the thyroid gland. It would be best not to combine data on both.

It is acknowledged that both types of well-differentiated carcinoma grow slowly and it is necessary to observe patients with these lesions over long periods of time to observe results of treatment and prognosis. It is frequently stated that the tumors in the older age group (40-45 years of age) are more serious. Might it be that many of these tumors are more advanced and first become apparent later in life-thus, increased mortality in patients 40-45 years of age or older? Even the illustrative case given in this article substantiates this fact: the onset of tumor at 6 years of age and death from the tumor at 36 (it could have been 40 years of age).

The authors advocate total thyroidectomy for all patients with differentiated cancer of the thyroid. Certainly, this approach is justified when secondary surgery is carried outwhich was true in many of their cases or in advanced lesions. However, their series of cases, 42 of 798 , represent only one-half of $1 \%$ of the total series. In the authors hands, the morbidity of total thyroidectomy is undoubtedly very low, but this would not be the experience of surgeons in general. The extent of the surgical procedure should be tailored to the extent of the primary lesions. Woolner [1] has reported 244 cancers of the thyroid $1 \frac{1}{2} \mathrm{~cm}$ or less in diameter, about $40 \%$ with regional nodule spread followed 40 years without a single death from thyroid cancer, essentially, all treated by less than total thyroidectomy. The emphasis should be on selective extent of thyroidectomy, depending on gross findings at the time of surgery.

Lastly, a scheme of staging of cancer of the thyroid has not been generally accepted. For this reason, all data reported in this and other articles is of limited value. The American Joint Committee on Cancer (AJCC) along with the TNM Committee 